\title{
COMMENTARY
}

\section{Professionalism Flows From Both The Profession's Identity and One's Professional Identity, But They Are Different}

\author{
Timothy J. Bloom, PhD ${ }^{\mathrm{a}, \mathrm{b}}$ \\ ${ }^{\text {a }}$ Bernard J. Dunn School of Pharmacy, Shenandoah University, Winchester, Virginia \\ ${ }^{\mathrm{b}}$ Editorial Board Member, American Journal of Pharmaceutical Education, Arlington, Virginia
}

Corresponding Author: Timothy J. Bloom, Bernard J. Dunn School of Pharmacy, Shenandoah University, 1775 N. Sector Ct., Winchester, VA 22601. Tel: 540-678-4395. Email: tbloom2@su.edu

Submitted November 12, 2021; accepted January 27, 2022; ePublished January 2022

Pharmacy schools have taught professionalism for many years, but are now discussing the model of professional identity formation adopted by academic medicine. The former is an outward expression of a community's norms while the latter is an internalization of those norms such that one thinks, acts, and feels like a member of the community. Some have expressed concern that the wide-ranging roles and responsibilities of pharmacists mean there is no universal identity for the pharmacy profession and that a student's professional identity therefore cannot be easily developed. This commentary suggests that the profession's identity is an outward expression to patients and other health care providers of what pharmacists do, while one's professional identity is an internal acceptance that being a pharmacist is who one is. The former may make the latter easier to develop, but is not required to begin guiding student pharmacists in the formation of their professional identity.

Keywords: professionalism, professional identity, pharmacy profession

It has been recognized for many years that teaching and assessing student pharmacists' professionalism is an important part of their education. ${ }^{1-8}$ Professionalism can be defined as the shared norms, attitudes and behaviors that members of a professional community express or display, allowing others to recognize them as part of that community. Schools devote considerable energy and resources to developing student professionalism, and have processes for dealing with students who demonstrate unprofessional behavior or violate a professionalism code. ${ }^{9}$

Academic medicine also taught professionalism for many years, but over the past decade began promoting development of students' professional identity. ${ }^{10,11}$ The medical education literature describes as one motivation for this change a recognition of the difference between external demonstrations of behaviors and attitudes (ie, professionalism) and an internalization of a professional community's norms (ie, a professional identity). ${ }^{10}$ This led to a concern that, in some instances, professionalism might merely be behavior expressed when someone is watching. Professionalism can be driven by the extrinsic motivation of others' expectations, which may lead to less professional behavior when one is unobserved. In contrast, someone with a strong professional identity has internalized the norms, attitudes and behaviors of their community. Individuals with a strong professional identity may be more likely to do the right thing according to the community's standards, because to violate the standards would make them feel as if they were betraying not only their community but also themselves. As Cruess and colleagues wrote, schools' efforts to direct medical students' professional identity formation will "serve to guide and reinforce emerging behavior patterns, indicating that an individual's perceptions of her or his actions, motives, and feelings are congruent with [the idea of a] 'good physician." 11

Academic pharmacy is now looking at medicine's example, and having a discussion about whether our development of student professionalism should be revised to guiding formation of a professional identity, such that graduates "think, act and feel" like a pharmacist. The American Association of Colleges of Pharmacy (AACP) Student Affairs Committee (SAC) was charged in 2019-2020 to "Outline key elements of professional identity formation that educators must be aware of in establishing student learning experiences that prepare them for interprofessional practice" and in 2020-2021 to "Examine strategies to support professional identity formation in our educational systems". In their reports, the committees summarized the literature on formation of both personal and professional identities. ${ }^{12,13}$

Welch and colleagues wrote in the 2020 SAC report that "Paramount to the advancement of [professional identity formation] is the need for the profession to evaluate and define the professional identity of the pharmacist." ${ }^{12}$ This could be misinterpreted to mean that work on students' professional identity formation should wait until a single identity is accepted for the pharmacy profession. Some may feel that for professional identity formation to be successful, there needs 
to be a widely accepted definition of a pharmacist, and therefore a single identity of the profession that all student pharmacists will adopt.

One problem with this interpretation of professional identity formation is a long-lasting disagreement about the identity of the pharmacy profession. Kellar and colleagues outline five different identities over the past century, each based on the primary (or newest) role of the pharmacist at that point in time. ${ }^{14}$ These are apothecary, dispenser, merchandiser, expert advisor, and health care provider. Several of these still describe how pharmacists are identified by patients and/or other health care providers today. Many patients readily think of the pharmacist as a "dispenser", since a common interaction is at the community pharmacy to pick up a prescription. Attendees at a meeting of any national pharmacy organization may see sessions on practicing to the top of the PharmD degree, and think of "expert advisor" or "health care provider" as the pharmacist's identity. Other health care professionals interact with pharmacists based in part on the roles they think pharmacists fill, while legislators and regulators decide what roles pharmacists are allowed based on their own perception of pharmacy.

It seems intuitive that an accepted identity for a profession helps contribute to the development of one's own professional identity. After having served on both the 2019-2020 and 2020-2021 SAC, I agree with the argument that a widely accepted identity for pharmacy could help student pharmacists better understand the community they are joining. Noble and colleagues reported that a misalignment of the identity of the pharmacy profession encountered in the classroom and on experiential rotations can slow development of students' professional identity. ${ }^{15}$ Students were taught in class about the identity of "expert adviser", but saw on many of their rotations only the roles and responsibilities of a "dispenser". A disconnect between what students were taught in class and what they experienced in practice led to confusion about the community they were trying to join, and thus their place in it. Kellar and colleagues also noted this effect on students, saying "in many cases, the health provider identity they aspire to during their education is in direct opposition to what they later experience in practice settings." 14

I agree that a universally accepted identity for pharmacists might also help members of other health care professions better understand what to expect when working with a pharmacist. Moore and colleagues urge that "We need to consciously expand our communication about who pharmacists are and what pharmacists do to those outside of the profession- to those who are not aware; to those who are being educated with future pharmacists; to those in other health care professions. With the requirement of interprofessional education for all health professions, the time is now to educate our colleagues in other professions about the pharmacist role and scope of practice." ${ }^{16}$ A widely accepted identity for pharmacy might enhance that communication, and thus the integration of pharmacists as members of the health care team, helping achieve the goal of previous AACP President Todd Sorenson "that by 2025, 50\% of primary care physicians in the U.S. will have a formal relationship with a pharmacist." 17

I have been in academic pharmacy for 25 years, and have worked with and taught many pharmacists in that time. I've seen the transition from pharmaceutical care to medication therapy management and now the Pharmacists Patient Care Process (PPCP), and the way these changes have affected how pharmacists talk about themselves. I believe that as it has in the past, any future identity of the pharmacy profession will likely focus largely on roles and responsibilities taken on by its members. However, although roles and responsibilities are important, they alone do not define an individual's professional identity. Being competent at roles and responsibilities can be achieved by thinking and acting like a pharmacist, but this alone does not ensure one has internalized the community's norms, attitudes and behaviors, and therefore feels like a pharmacist. As an oversimplification, a profession's identity is a sort of brand, making it possible to explain to others what one does. In contrast, having a professional identity means that one describes being a member of that profession as part of who they are. Two pharmacists in different practice environments filling completely different roles can each think, act and feel like a pharmacist, meaning they have a professional identity. Despite differences in their roles and responsibilities, and perhaps in how they would each define the identity of the pharmacy profession, they both demonstrate the shared norms, attitudes and behaviors associated with being a pharmacist.

In the absence of a singular identity for the pharmacy profession, it is worth considering whether the student pharmacists studied by Noble and colleagues would have been as confused about the profession and their place in it if they had been aware of the breadth of practice conditions, roles, and responsibilities they would encounter outside of the classroom. Unless and until there is a widely accepted identity for the pharmacy profession, schools should make clear that pharmacists have roles as "dispensers" as well as "expert advisors" and "health care providers". Preceptors are offered continuing education opportunities by the schools whose students they train, and in return could provide feedback on the current real-world state of pharmacy, so students do not experience culture shock on rotations. Based on the observations of Nobel and colleagues, this simple awareness could go a long way toward helping student pharmacists develop their professional identity.

Welch and colleagues wrote in the 2019-2020 SAC report of the importance of addressing both the profession's identity and students' professional identity. ${ }^{12}$ However, the identity of a profession is distinct from an individual's 
professional identity, and the two should not be conflated. The identity of the profession can be decided through a discussion amongst the various pharmacy stakeholders, including the academy. This might parallel the process used by the Joint Commission of Pharmacy Practitioners during the development of the PPCP, and should be driven by pharmacy practitioners both within the Academy and outside it. It is they who develop interprofessional relationships and thus benefit from the "brand awareness" of those in other health care professions. It would also help them more clearly communicate with the patients who seek their care and the legislators who regulate the roles and responsibilities of the pharmacist.

In contrast, an individual's identity, whether personal or professional, is developed over time through interactions with others, and evolves in response to both internal and external feedback from those interactions. Successful professional identity formation begins with exploration of a community, continues as a place in that community is initiated and then established, and results in acceptance by others in the community and a feeling that one belongs there. For each individual, developing a professional identity involves the teachers, preceptors, patients, and other health care providers with whom they interact throughout their career. The variety of these interactions alone means it will not be possible for schools and colleges to guide their students toward one professional identity that is shared by all.

In addition, we must remember the bi-directional interplay between personal identity and professional identity. One's professional identity cannot be stable and resilient if there are significant conflicts between it and one's personal identity, and vice versa. Frost and Regehr wrote that one's personal and professional identities cannot be completely compartmentalized from each other. They argue that "medical education should be organized and delivered in ways that encourage the incorporation, preservation, and leveraging of students' idiosyncrasies. If differences are effaced or negated through medical training then the benefits of admitting diverse students fail to be realized." ${ }^{18}$ The recognition of the impact of the personal identity on the professional identity has also played a role in the move in academic medicine from professionalism to professional identity. As Bhatia-Lin and colleagues wrote, "Physician [professional identity formation] has historically been racialized and gendered to reflect the White male physicians who dominated the occupation and to maintain an overrepresentation among its leadership." "The importance of this cannot be overstated as we work to enhance equity, inclusion and diversity in our application pipeline and our curricula. It can be easier for individuals to start exploring a place for themselves in a professional community if they can readily see others who seem to share one or more aspects of their personal identity.

As a consequence of the individuality of the longitudinal process of identity formation, and the impact of personal identity and professional identity on each other, even if there is one widely accepted identity for the pharmacy profession, it is unlikely there will be one universal professional identity that applies to all pharmacists, or even those who work in similar practice sites. Since pharmacists fulfilling different roles and responsibilities can all have strong professional identities, schools and colleges of pharmacy do not need to have a universal definition of pharmacy's identity before starting the work of intentionally developing their students' professional identity. During the ongoing discussions about what it means to be a pharmacist, we should be having parallel but distinct conversations about how to help our students think, act and feel like a pharmacist, regardless of where they practice.

\section{REFERENCES}

1. Hill WT. White paper on pharmacy student professionalism: what we as pharmacists believe our profession to be determines what it is. J Am Pharm Assoc. 2000;40(1):96-102. doi:10.1016/S10865802(16)31043-9

2. Hammer DP, Berger BA, Beardsley RS, Easton MR. Student professionalism. Am J Pharm Educ. 2003;67(3):96.

3. Kelley KA, DeBisschop M, Donaldson AR, et al. Professional socialization of pharmacy students: do we have the right ingredients AND the right formula for success? Curr Pharm Teach Learn. 2009;1(2):103-109.

doi:10.1016/J.CPTL.2009.10.005

4. Popovich NG, Hammer DP, Hansen DJ, et al. Report of the AACP professionalism task force, May 2011. Am J Pharm Educ. 2011;75(10):1-4.

5. Akiyode O. Teaching professionalism: a faculty's perspective. Curr Pharm Teach Learn. 2016;8(4):584-586. doi:10.1016/J.CPTL.2016.03.011

6. Eukel H, Frenzel J, Skoy E, Faure M. Longitudinal evaluation of student professionalism throughout the professional didactic curriculum of a pharmacy program. Curr Pharm Teach Learn. 2018;10(3):325-332. doi:10.1016/J.CPTL.2017.11.011

7. Smith KJ, Flaxman C, Farland MZ, et al. Development and validation of a situational judgement test to assess professionalism. Am J Pharm Educ. 2020;84(7):985-992. doi:10.5688/ajpe7771 
8. Zeeman JM, Kiser SN, Steeb DR, Hubal R. Identifying priority student leadership and professionalism attributes among faculty, preceptors, and students via modified Delphi. Am J Pharm Educ. 2020;84(11):1523-1531. doi:10.5688/ajpe8076

9. Curtis SD, Li RM, Miller SA. Professionalism development through the curriculum: developing a new system for identifying and tracking professional behavior lapses. Curr Pharm Teach Learn. 2021;13(5):445-448. doi:10.1016/J.CPTL.2021.01.014

10. Jarvis-Selinger S, Pratt DD, Regehr G. Competency is not enough. Acad Med. 2012;87(9). doi:10.1097/ACM.0b013e3182604968

11. Cruess RL, Cruess SR, Boudreau JD, Snell L, Steinert Y. Reframing medical education to support professional identity formation. Acad Med. 2014;89(11). doi:10.1097/ACM.0000000000000427

12. Welch BE, Arif SA, Bloom TJ, et al. Report of the 2019-2020 AACP Student Affairs Standing Committee. Am J Pharm Educ. 2020;84(10):1402-1408. doi:10.5688/ajpe8198

13. Janke KK, Bloom TJ, Boyce EG, et al. A Pathway to Professional Identity Formation: Report of the 2020-2021 AACP Student Affairs Standing Committee. Am J Pharm Educ. July 2021(PAP). doi:10.5688/ajpe8714

14. Kellar J, Paradis E, van der Vleuten CPM, oude Egbrink MGA, Austin Z. A historical discourse analysis of pharmacist identity in pharmacy education. Am J Pharm Educ. 2020;84(9):1251-1258. doi:10.5688/ajpe7864

15. Noble C, O’Brien M, Coombes I, Shaw PN, Nissen L, Clavarino A. Becoming a pharmacist: students' perceptions of their curricular experience and professional identity formation. Curr Pharm Teach Learn. 2014;6(3):327-339. doi:10.1016/J.CPTL.2014.02.010

16. Moore GD, Bradley-Baker LR, Gandhi N, et al. Pharmacists are not mid-level providers. Am J Pharm Educ. July 2021(PAP). doi:10.5688/ajpe8556

17. Sorensen TD. Leading in dickensian times: address of the president-elect at the 2019 AACP Annual Meeting. Am J Pharm Educ. 2019 Aug; 83(6):1414-1416.

18. Frost HD, Regehr G. "I AM a doctor." Acad Med. 2013;88(10). doi:10.1097/ACM.0b013e3182a34b05

19. Bhatia-Lin A, Wong K, Legha R, Walker VP. What will you protect? redefining professionalism through the lens of diverse personal identities. MedEdPORTAL. 2021;17:11203. Published 2021 Dec 2. doi:10.15766/mep_23748265.11203 